\title{
Growth Morphology of Ultrathin Pb Layers on Ni(001)
}

\author{
K. KRUPSKI ${ }^{a, b, *}$, T. KobIEla ${ }^{c}$ AND A. KRUPSKI ${ }^{a, b}$ \\ ${ }^{a}$ Department of Physics, University of Warwick, Coventry CV4 7AL, United Kingdom \\ ${ }^{b}$ Institute of Experimental Physics, University of Wrocław, pl. M. Borna 9, PL 50-204 Wrocław, Poland \\ ${ }^{c}$ Faculty of Chemistry, Warsaw University of Technology, S. Noakowskiego 3, 00-664 Warsaw, Poland
}

(Received September 26, 2013; in final form November 7, 2013)

\begin{abstract}
The atomic structure and morphology of ultrathin $\mathrm{Pb}$ layers deposited on the $\mathrm{Ni}(001)$ face in ultrahigh vacuum at the substrate temperature, ranging from $145 \mathrm{~K}$ to $900 \mathrm{~K}$, were investigated with the use of the Auger electron spectroscopy and low-energy electron diffraction. The analysis of the Auger electron spectroscopy measurements indicates that the Volmer-Weber growth of the $\mathrm{Pb}$ takes place for substrate temperature $T<300 \mathrm{~K}$. Between 300 and $600 \mathrm{~K}$, the Stranski-Krastanov growth mode is observed. For $600 \mathrm{~K} \leq T \leq 700 \mathrm{~K}$, only first two-dimensional $\mathrm{Pb}$ layer formation is found. Above $700 \mathrm{~K}$ desorption of lead atoms from the first layer is observed. The ordered low-energy electron diffraction patterns corresponding to $\mathrm{p}(1 \times 1)$ and $\mathrm{c}(2 \times 2)$ structures are observed.
\end{abstract}

DOI: $10.12693 /$ APhysPolA.125.1159

PACS: 68.35.B-, 68.35.bd, 68.35.Ct, 68.43.Mn, 68.47.De, 68.65.Ac

\section{Introduction}

Metal atoms adsorbed on solid surfaces are important and interesting in many respects. They represent the very beginning of metal deposition, and their nucleation and growth behaviour determine the structure and properties of the modified surface. Such surfaces with monolayers of foreign metals often exhibit unique and interesting properties that are absent in unmodified bare surfaces. Growth of lead layers have received increasing attention in recent years, because the islands formed during growth are of a special uniform height (often referred to as a "magic" island) with flat tops and step edges. This phenomenon has been observed during metal thin-film growth in a few material systems such as $\mathrm{Pb} / \mathrm{Ni}(111)$ [1-3], $\mathrm{Pb} / \mathrm{Ni}_{3} \mathrm{Al}(111)$ [4, 5], $\mathrm{Pb} / \mathrm{Mo}(110)$ $[6,7], \mathrm{Pb} / \mathrm{Cu}(111)$ [8-10], $\mathrm{Pb} / \mathrm{Si}(111)$ [10-21], and has been interpreted in terms of quantum size effects (QSE) [22-27].

These studies indicate that, in the equilibrium distribution of island heights, some heights appear much more frequently than others. "Magic" preferred heights correspond to islands with a quantum well state far from the Fermi energy, while "forbidden" heights appear to be those that have a quantum well state close to the Fermi level. Until now, ultrathin lead layers deposited on the $\mathrm{Ni}(001)$ face have been studied in a few works [28-31]. However, those investigations were limited only to lead layers deposited at room temperature and were mainly concentrated below the first $\mathrm{Pb}$ monolayer.

In the present paper there will be shown the results of investigating the structure and morphology of ultrathin $\mathrm{Pb}$ layers deposited on the $\mathrm{Ni}(001)$ face in ultrahigh vacuum at the substrate temperature ranging from $145 \mathrm{~K}$ to $900 \mathrm{~K}$ and coverage up to $5 \mathrm{ML}$. These results were

*corresponding author; e-mail: k.j.krupski@warwick.ac.uk obtained with the use of the Auger electron spectroscopy (AES) and low-energy electron diffraction (LEED).

\section{Experimental}

The measurements were carried out in a metal ultrahigh-vacuum chamber with the base pressure of $2 \times 10^{-8} \mathrm{~Pa}$. The chamber was equipped with the reverse view LEED optics (OCI Vacuum Micro engineering) which was used for both LEED and AES measurements.

The spot size of the primary electron beam in case of LEED and AES measurements was equal to $0.5 \mathrm{~mm}$. The $\mathrm{Ni}(001)$ single crystal was mounted on a manipulator [32], with facilities for its rotation around axes parallel and perpendicular to its surface. The equipment allowed for the sample temperature to be between $145 \mathrm{~K}$ and $1150 \mathrm{~K}$. The crystal temperature was measured by using an $\mathrm{NiCr}-$ Ni thermocouple. The crystal was cleaned by potassium ion bombardment from a zeolite source $(5 \mu \mathrm{A}, 660 \mathrm{eV})$ and by simultaneous annealing at $900 \mathrm{~K}$. This procedure was repeated until the carbon peak was no longer visible in the AES spectrum, and a LEED pattern with sharp spots and low background appeared.

Lead $(99.999 \%)$ was evaporated onto the crystal surfaces from the same quartz crucible surrounded by a tungsten resistive heater in a vacuum of $5 \times 10^{-8} \mathrm{~Pa}$ or better, and at a deposition rate of $2.66 \times 10^{-3} \mathrm{ML} / \mathrm{s}$. For thickness measurements of adsorbed layers the $\operatorname{AES}(t)$ plots were used in present studies according to well described formalism [33-37].

Owing to the geometry of the system, it was possible during the deposition of lead on the sample surface, to record either the Auger peak heights under computer control for nickel $M V V$ transition at $61 \mathrm{eV}$ and lead $N V V$ transition at $94 \mathrm{eV}$, or LEED patterns in the computer memory with the use of a CCD camera. The Auger peak height for nickel was corrected for the background, created by the secondary electrons in the low-energy part of the $d N / d E$ versus electron energy curve. In our measurement, the adsorbate deposition is not interrupted for 
the recording of the Auger peaks. Thus the $\operatorname{AES}(t)$ plots are shown for a continuous growth of the deposited layer.

\section{Results and discussion}

Plotting the AES peak heights of the substrate and the adsorbate as a function of deposition time - $\operatorname{AES}(t)$ plots - enables the determination of the growth mechanism, as well as the monolayer formation [33-37]. At a deposition temperature of $T<200 \mathrm{~K}, \mathrm{~Pb}$ on $\mathrm{Ni}(001)$ grows in the Volmer-Weber (VW) [38, 39] mode, as shown by monotonic parts of the $\operatorname{AES}(t)$ plots for $61 \mathrm{eV}$ nickel and $94 \mathrm{eV}$ lead peaks (Fig. 1a). For temperatures between $300 \mathrm{~K} \leq T \leq 600 \mathrm{~K}$, the first linear part of the $\operatorname{AES}(t)$ plots for $\mathrm{Ni}$ and $\mathrm{Pb}$ peaks can be observed, respectively (Fig. 1b and c), suggesting the presence of two-dimensional (2D) growth of the first lead layer. Thus, if $\alpha_{S}^{\mathrm{A}}=h_{S 1} / h_{S 0}$ defines the coefficient of attenuation of the substrate Auger peak, owing to the presence of a monolayer of adsorbate, then the expected height of the substrate Auger peak for layer-by-layer growth, after completion of the $n=2 \mathrm{nd}, 3 \mathrm{rd}, 4 \mathrm{th}, \ldots$ layer, is given by the equation $h_{S n}=h_{S 0}\left(\alpha_{S}^{\mathrm{A}}\right)^{n}\left[33^{-39]}\right.$.

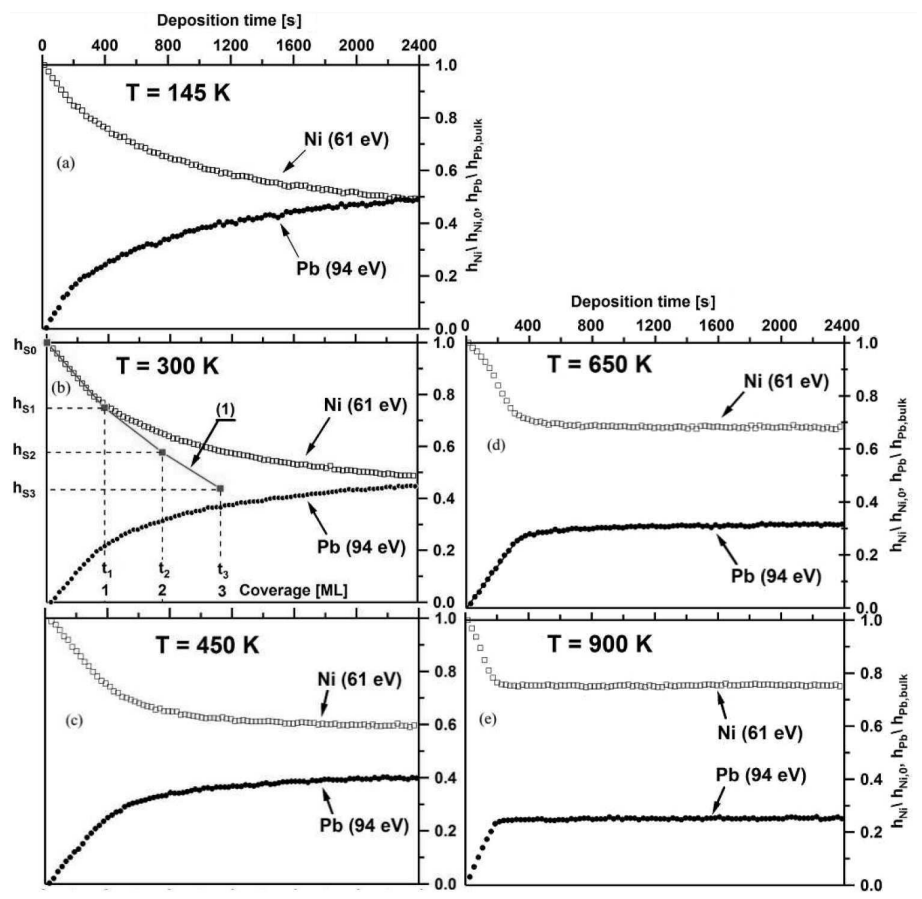

Fig. 1. $\operatorname{AES}(t)$ plots of $\mathrm{Ni} M V V$ and $\mathrm{Pb} N V V$ peak heights for lead deposition on $\mathrm{Ni}(001)$ face at: (a) $T=$ $145 \mathrm{~K}$, (b) $T=300 \mathrm{~K}$, (c) $T=450 \mathrm{~K}$, (d) $T=650 \mathrm{~K}$, (e) $T=900 \mathrm{~K} . h_{1}$ and $t_{1}$ correspond to the first monolayer (ML) of lead. (1) $\operatorname{AES}(t)$ plot calculated for the Frank-van der Merwe growth.

Curve 1 in Fig. 1b is calculated for FM growth using the formula described above, under the assumption that, at the $\left(h_{S 1} ; t_{1}\right)=(0.75 ; 375)$, point the first lead layer is completed. Since the scatter of $h_{S_{1}}$ and $t_{S_{1}}$ values for particular $\operatorname{AES}(t)$ plots is not large for $T \leq 600 \mathrm{~K}$, we will suppose further that the first linear part of the curve corresponds to the formation of the first layer $(\theta=1 \mathrm{ML})$ of lead, where a $1 \mathrm{ML}$ of $\mathrm{Pb}(001)$ film corresponds to an atomic packing density of $8.1 \times 10^{14}$ atoms $/ \mathrm{cm}^{2}$.

Further, the nonlinear shape of the $\operatorname{AES}(t)$ plots for temperature $300 \mathrm{~K} \leq T<600 \mathrm{~K}$ implies a three-dimensional (3D) growth mode (Stranski-Krastanov (SK) mode [40]). The AES( $t$ ) plot of the substrate calculated for layer-by-layer growth does not fit the experimentally found $\operatorname{AES}(t)$ plot (curve 1 in Fig. 1b).

For $600 \mathrm{~K} \leq T \leq 700 \mathrm{~K}$, the $\operatorname{AES}(t)$ plots saturate after the first two-dimensional lead layer completion (Fig. 1d). For $T>700 \mathrm{~K}$ the equilibrium coverage with lead becomes smaller than $1 \mathrm{ML}$, and decreases with increasing temperature. This can be explained by the thermal desorption of the first lead layer (Fig. 1e).

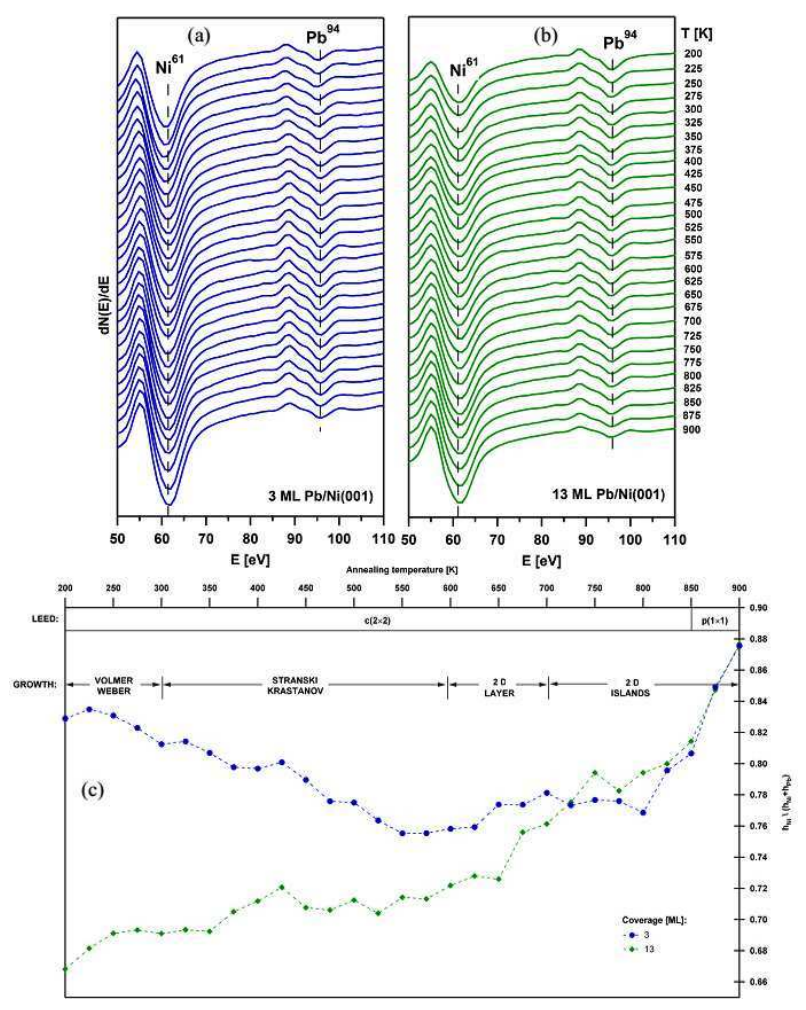

Fig. 2. Set of AES scans as a function of the annealing temperature for (a) $3 \mathrm{ML}$ and (b) $13 \mathrm{ML}$ of $\mathrm{Pb}$ on the $\mathrm{Ni}(001)$ deposited at $T=200 \mathrm{~K}$. (c) AES peak height ratio as a function of annealing temperature for 3 and 13 ML coverage.

This supposition has been confirmed by set of AES scans as a function of the annealing temperature for 3 and $13 \mathrm{ML}$ of $\mathrm{Pb}$ on the $\mathrm{Ni}(001)$ deposited at $T=200 \mathrm{~K}$, and AES peak height ratio as a function of annealing temperature for both coverage in Fig. 2. It should be pointed out here that, for deposition temperature $T=650 \mathrm{~K}$, the nonlinear shape of the substrate $\operatorname{AES}(t)$ plot and, simultaneously, the linear shape of the adsorbate $\operatorname{AES}(t)$ plot has been observed repeatedly in our experiments for the first linear segment corresponding to the first monolayer formation (Fig. 1d). The same effect has been observed 
for the $\mathrm{Pb} / \mathrm{Ni}(111) \operatorname{AES}(t)$ plots [3], demonstrating the similarity of the two adsorption systems. The reason for nonlinear signal from the Ni substrate in the initial stage of $\mathrm{Pb}$ deposition at $T=650 \mathrm{~K}$ could be the rearrangement of $\mathrm{Pb}$ atoms on the surface.

(a)

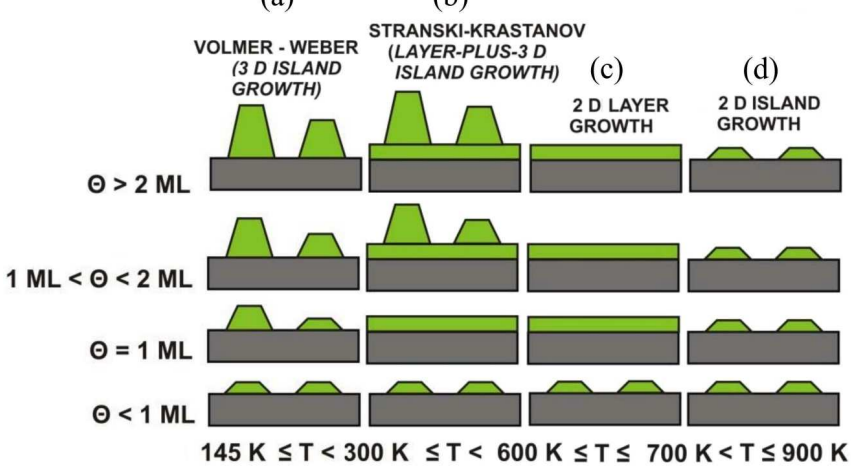

Fig. 3. Schematic representations of (a) VolmerWeber, (b) Stranski-Krastanov, (c) 2D layer and (d) 2D island growth modes of $\mathrm{Pb}$ on the $\mathrm{Ni}(001)$ surface as a function of deposition temperature. Growth morphology is deduced from the $\operatorname{AES}(t)$ plots shown in Fig. 1.

Schematic representations of Volmer-Weber, StranskiKrastanov, 2D layer and 2D island growth modes of $\mathrm{Pb}$ on the $\mathrm{Ni}(001)$ surface as a function of deposition temperature deduced from the $\operatorname{AES}(t)$ plots is shown in Fig. 3. Lead atoms on the $\mathrm{Ni}(001)$ face form ordered structures after evaporation onto the crystal face.
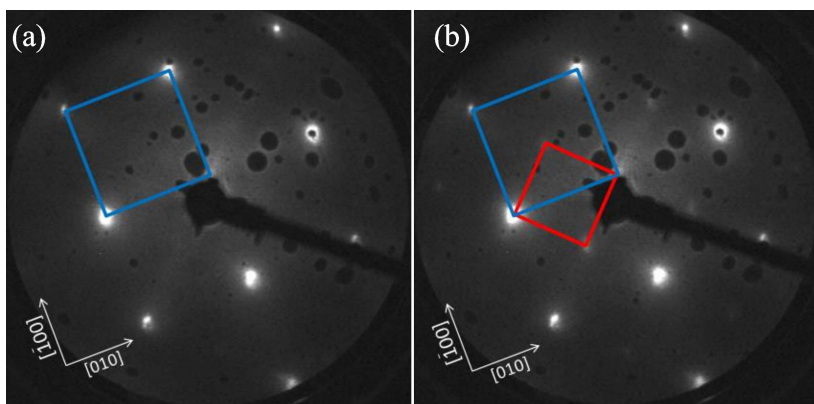

Fig. 4. LEED patterns observed during the growth of $\mathrm{Pb}$ on the $\mathrm{Ni}(001)$ surface, recorded for normal electron incidence, electron energy $E=120 \mathrm{eV}$ and sample temperature $T=200 \mathrm{~K}$ : (a) clean $\mathrm{Ni}(001)$, (b) c $(2 \times 2)-\mathrm{Pb}$. The unit cells of the substrate (blue) and lead lattice (red) are indicated.

Typical LEED patterns observed after deposition of lead on the $\mathrm{Ni}(001)$ face in normal electron incidence are shown in Fig. 4. The patterns are shown to demonstrate the quality of the structural order at the surface.

The corresponding structure model for the clean $\mathrm{Ni}(001)$ surface and $\mathrm{c}(2 \times 2)$ structure of $\mathrm{Pb}$ are shown in Fig. 5a and b, respectively. The lattice constant of the clean $\mathrm{Ni}(001)$ surface unit cell is $3.58 \AA$. At the sam-

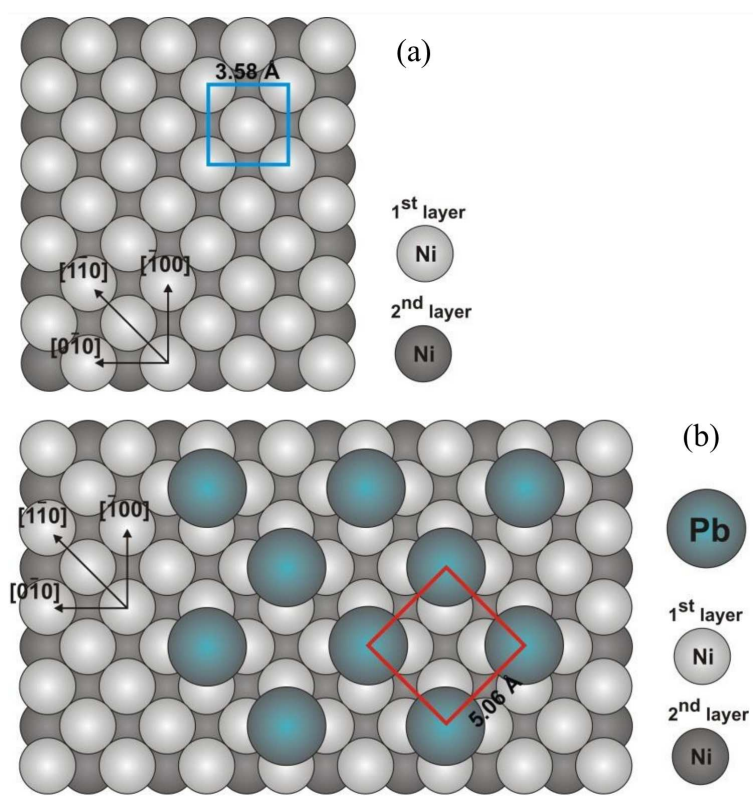

Fig. 5. Top view of surface structures deduced from the LEED patterns shown in Fig. 3: (a) clean $\mathrm{Ni}(001)$, (b) $\mathrm{c}(2 \times 2)-\mathrm{Pb}$. The unit cells of the substrate (blue) and lead lattice (red) are shown in each diagram.

ple temperature between 200 and $850 \mathrm{~K}$, for coverage $\Theta \geq 1.0 \mathrm{ML}$, the structure $\mathrm{c}(2 \times 2)$ is visible in the LEED patterns. The strongest intensity of spots for the $\mathrm{c}(2 \times 2)$ structure was observed for coverage of $\mathrm{Pb}$ equal to $1.0 \mathrm{ML}$. At coverage $\theta>3.0 \mathrm{ML}$, the overlayer diffraction spots are invisible, while the very weak spots of the substrate structure are visible up to a coverage of about $5 \mathrm{ML}$. This is in agreement with the island growth as deduced from AES analysis. At coverage of $\theta>5 \mathrm{ML}$ the overlayer spots and the spots of the substrate structure are not visible. After deposition of lead on the $\mathrm{Ni}(001)$ at the sample temperature $T \geq 850 \mathrm{~K}$ (or after annealing at $T \geq 850 \mathrm{~K}$, the $\mathrm{Pb}$ layer deposited at $T<600 \mathrm{~K}$ ) diffraction patterns corresponding to the $c(2 \times 2)$ structure are observed. Atomic spacings and angles presented in the hard-sphere models of Fig. 5 agree with the LEED patterns shown in Fig. 4 . For the $\mathrm{c}(2 \times 2)$ structure, the density of $\mathrm{Pb}$ atoms is $3.9 \times 10^{14}$ atom $/ \mathrm{cm}^{2}$, which is $48 \%$ of the density of the close-packed (001) $\mathrm{Pb}$ layer. The growth mode of one metal evaporated onto another is governed by the surface free energies, strain energies, and kinetics [41]. Thermodynamically, the growth mode of adsorption systems is determined by the surface free energies of the substrate $\gamma_{\mathrm{s}}$, the adsorbate $\gamma_{\mathrm{a}}$, and the interface energy $\gamma_{i}$ [41]. In general, if the interface energy $\left(\gamma_{\mathrm{i}}\right)$ is less than zero, the system is stabilized by intermixing, maximizing the interface between the adsorbate and the substrate atoms [42]. However, typically the interface energy $\gamma_{\mathrm{i}}$ is not known. In addition, strain energy, owing to the atomic size mismatch (or the lattice constant mismatch) between the adlayer 
and the substrate atoms, can also induce intermixing at the surface [43]. This leads to a situation where the growth of the first two-dimensional lead is also driven thermodynamically by the lower surface free energy of $\mathrm{Pb}\left(0.377 \mathrm{~J} / \mathrm{m}^{2}<\gamma_{\mathrm{Pb}}<0.600 \mathrm{~J} / \mathrm{m}^{2}\right)$ [44-47] compared to $\mathrm{Ni}(001)\left(2.38 \mathrm{~J} / \mathrm{m}^{2}<\gamma_{\mathrm{Ni}(001)}<2.45 \mathrm{~J} / \mathrm{m}^{2}\right)[44-46]$ so that the $\mathrm{Pb}$ layer wets the $\mathrm{Ni}(001)$ surface, despite the elastic energy required, as a result of the large lattice mismatch between $\mathrm{Pb}$ and $\mathrm{Ni}(001), \approx 28 \%$ (for fcc $\mathrm{Pb}$, $a_{\mathrm{Pb}}=4.95 \AA$, for fcc Ni(001), $\left.a_{\mathrm{Ni}}=3.58 \AA\right)[44,48]$.

\section{Conclusions}

The AES results indicate that the growth of the lead layer on the $\mathrm{Ni}(001)$ face strongly depends on the substrate temperature. For substrate temperature $T<$ $300 \mathrm{~K}$, the $\mathrm{VW}$ growth of the $\mathrm{Pb}$ is observed. Between 300 and $600 \mathrm{~K}$, the SK growth mode is visible. For $600 \mathrm{~K} \leq T \leq 700 \mathrm{~K}$, only first two-dimensional $\mathrm{Pb}$ layer formation is found. Above $700 \mathrm{~K}$ desorption of lead atoms from the first layer is observed. The ordered LEED patterns corresponding to $\mathrm{p}(1 \times 1)$ and $\mathrm{c}(2 \times 2)$ structures are observed.

\section{References}

[1] T.R.J. Bollmann, R. Gastel, H.J.W. Zandvliet, B. Poelsema, New J. Phys. 13, 103025 (2011).

[2] T.R.J. Bollmann, R. Gastel, H.J.W. Zandvliet, B. Poelsema, Phys. Rev. Lett. 107, 136103 (2011).

[3] A. Krupski, S. Mróz, Phys. Rev. B 66, 035410 (2002).

[4] K. Miśków, A. Krupski, Appl. Surf. Sci. 273, 554 (2013).

[5] K. Miśków, A. Krupski, K. Wandelt, Vacuum 101 , 71 (2014).

[6] A. Krupski, Phys. Rev. B 80, 035424 (2009).

[7] A. Krupski, Surf. Sci. 605, 1291 (2011).

[8] B.J. Hinch, C. Koziol, J.P. Toennies, G. Zhang, Europhys. Lett. 10, 341 (1989).

[9] R. Otero, A.L. Vázquez de Parga, R. Miranda, Phys. Rev. B 66, 115401 (2002).

[10] B. Slomski, G. Landolt, S. Muff, F. Meier, J. Osterwalder, J.H. Dil, arXiv:1306.0245 [cond-mat.mtrl-sci] (2013).

[11] Z. Kuntova, M. Hupalo, Z. Chvoj, M.C. Tringides, Surf. Sci. 600, 4765 (2006).

[12] K. Budde, E. Abram, V. Yeh, M.C. Tringides, Phys. Rev. B 61, 602 (2000).

[13] A. Menzel, M. Kammler, E.H. Conrad, V. Yeh, M. Hupalo, M.C. Tringides, Phys. Rev. B 67, 165314 (2003).

[14] T.-L. Chan, C.Z. Wang, M. Hupalo, M.C. Tringides, K.M. Ho, Phys. Rev. Lett. 96, 226102 (2006).

[15] S.M. Binz, M. Hupalo, M.C. Tringides, Phys. Rev. B 78, 193407 (2008).

[16] W.B. Su, S.H. Chang, W.B. Jian, C.S. Chang, L.J. Chen, T.T. Tsong, Phys. Rev. Lett. 86, 5116 (2001).

[17] J. Kim, S. Qin, W. Yao, Q. Niu, M.Y. Chou, Ch. Shih, Proc. Natl. Acad. Sci 107, 12761 (2010).
[18] M.M. Özer, Y. Jia, B. Wu, Z. Zhang, H.H. Weitering, Phys. Rev. B 72, 113409 (2005).

[19] M. Kesaria, M. Kumar, Govind, S.M. Shivaprasad, Appl. Surf. Sci. 256, 576 (2009).

[20] M. Hupalo, M.C. Tringides, Phys. Rev. B 75, 235443 (2007).

[21] M. Li, C.Z. Wang, J.W. Evans, M. Hupalo, M.C. Tringides, K.M. Ho, Phys. Rev. B 79, 113404 (2009).

[22] J.H. Dil, J.W. Kim, S. Gokhale, M. Tallarida, K. Horn, Phys. Rev. B 70, 045405 (2004).

[23] Y. Jia, B. Wu, H.H. Weitering, Z. Zhang, Phys. Rev. B 74, 035433 (2006).

[24] B. Wu, Z. Zhang, Phys. Rev. B 77, 035410 (2008).

[25] T.-C. Chiang, Surf. Sci. Rep. 39, 181 (2000).

[26] M. Milun, P. Pervan, D.P. Woodruff, Rep. Prog. Phys. 65, 99 (2002).

[27] G. Materzanini, P. Saalfrank, P.J.D. Lindan, Phys. Rev. B 63, 235405 (2001).

[28] J. Perdereau, I. Szymerska, Surf. Sci. 32, 247 (1972).

[29] P.J. Eng, P.W. Stephens, T. Tse, Phys. Rev. B 46 , 5024 (1992).

[30] T. Tse, P. Stephens, P.J. Eng, J. Phys., Condens. Matter 6, 6111 (1994).

[31] C. Argile, Surf. Sci. 398, 221 (1998).

[32] H. Otop, S. Mróz, A. Mróz, A. Krupski, Electron Technol. 33, 437 (2000).

[33] C. Argile, G.E. Rhead, Surf. Sci. Rep. 10, 277 (1989).

[34] T.E. Gallon, Surf. Sci. 17, 486 (1969).

[35] D.C. Jackson, T.E. Gallon, A. Chambers, Surf. Sci. 36, 381 (1973).

[36] M.P. Seah, Surf. Sci. 32, 703 (1972).

[37] J.B. Biberian, G.A. Somorjai, Appl. Surf. Sci. 2, 352 (1979).

[38] M. Volmer, A. Weber, Z. Phys. Chem. 119, 277 (1926).

[39] M. Harsdorff, Thin Solid Films 90, 1 (1982).

[40] J.N. Stranski, L. Krastanov, Ber. Akad. Wiss. Vien 146, 797 (1938).

[41] H. Roeder, R. Shuster, H. Brune, K. Kern, Phys. Rev. Lett. 71, 2086 (1993).

[42] E. Bauer, Appl. Surf. Sci. 11/12, 479 (1982).

[43] J. Tersoff, Phys. Rev. Lett. 74, 434 (1995).

[44] L. Vitos, A.V. Ruban, H.L. Skriver, J. Kollar, Surf. Sci. 411, 186 (1998).

[45] W.R. Tyson, W.A. Miller, Surf. Sci. 62, 267 (1977).

[46] F.R. de Boer, R. Boom, W.C.M. Mattens, A.R. Miedma, A.K. Niessen, Cohesion in Metals, North-Holland, Amsterdam 1988.

[47] Q. Jiang, H.M. Lu, M. Zhao, J. Phys., Condens. Matter 16, 521 (2004).

[48] C. Kittel, Introduction to Solid State Physics, 7th ed., Wiley, New York, 1996, p. 23. 